\title{
Zbirka isprava u Arhivu Provincije franjevaca trećoredaca glagoljaša
}

\begin{abstract}
U Arhivu Provincije franjevaca trećoredaca glagoljaša na Ksaveru u Zagrebu čuva se zbirka pergamena, odnosno diplomatičkih dokumenata sastavljenih latinskim i talijanskim jezikom. Isprave su iz dugoga vremenskoga razdoblja od 14. do kraja 18. stoljeća. Na temelju uvida u arhivsko pomagalo, odnosno u njihov inventar, kao i u samo gradivo procijenit će se ova diplomatička zbirka koja, čini se - kako su istaknuli sastavljači inventara - odražava povijest same Provincije. Ovu bi zbirku trebalo valorizirati i s njome upoznati znanstvenu javnost, kako bi postala predmetom istraživanja onima koji se bave prostorima i vremenima rasprostiranja Provincije.
\end{abstract}

U Arhivu Provincije franjevaca trećoredaca glagoljaša na Ksaveru u Zagrebu čuva se zbirka pojedinačnih diplomatičkih dokumenata, uglavnom napisanih na pergameni i nekoliko njih na papiru. Sastavljeni su pretežno latinskim, ali i talijanskim jezikom, ovisno o vremenu i prostoru gdje su i kada izdani. Ova arhivska zbirka nastala je objedinjavanjem dokumenata sakupljenih iz različitih samostana provincije. Obuhvaćaju dugo vremensko razdoblje od pet stoljeća, odnosno od početka 14. do kraja 18. stoljeća. Godine 1971. fra Anđelko Badurina (1935. 2013.) predao ih je Arhivu Hrvatske (danas Hrvatski državni arhiv) u Zagrebu na uvid i restauraciju. One su arhivistički obrađene, što znači da je po pravilima struke napravljen inventar s datacijom, regestom i najvažnijim elementima vanjskog opisa. U Arhivu provincije signirali su ih fra Marko Mišerda (1954. - 1989.) i fra Petar Runje (1938. - 2014.). Inventar s navedenim elementima objavljen je kao prilog Vjesnika franjevaca trećoredaca za 1979. i $1980 .{ }^{1}$ Iz tog popisa dokumenata dobiva se vrlo dobar uvid u njihov sadržaj, a time i u važnost koju imaju za istraživanje povijesti samih trećoredaca, ali i šireg okruženja u kojemu su nastali. To su u prvom redu Zadar i zadarsko otočje te sjevernojadranski otoci. Neke od ovih isprava svjedoče o vremenu i načinu nastanka pojedinih samostana. One su integralno objavljene kod fra Stjepana M. Ivančića (1852. - 1925.) te su tako postale dostupnije široj znanstvenoj javnosti, koja se njima koristila pri svojim

\footnotetext{
Arhiv Provincije franjevaca trećoredaca-Regeste pergamena. 1980. Ur. Petar Runje. Zagreb: Provincijalat franjevaca trećoredaca (umnoženo kao prilog Vjesnika franjevaca trećoredaca 3-4, 5-6 [1979]; 1-2 [1980]).
} 
istraživanjima te ih nadopunjavala podacima iz drugih arhivskih fondova. Pritom mislim na radove fra Petra Runje, fra Anđelka Badurine, Emila Hilje i drugih.

Uvidom u sastavljene regeste i tek ovlaš u same izvornike možemo steći opći dojam o važnosti ovih dokumenata. Već površan pogled na mjesto i vrijeme izdavanja dokumenata zrcali povijesni okvir same provincije. Najveći ih je broj izdan u Zadru i to pred javnim općinskim notarima. Prema notarskim znakovima i potpisima, nižu se imena notara Blaža, Petra de Annolonisa (?), Teodora de Prandina, Gabrijela Petrova iz Ferrare, Kristofora i drugih zadarskih javnih službenika. Osim Zadra, kao mjesta izdavanja isprava pojavljuju se ona gdje su bili trećoredski samostani, kao npr. Osor (Bijar), Cres (Martinšćica), Šibenik (Sustipanac), Rab (Komrčar), Glavotok, Dubašnica (Porat), Krk, ali i Knin. Zagonetno je da, osim Kopra, nema nijednoga napisanog iz drugih trećoredskih samostana u Istri (Božje Polje i Novigrad). Dakako, ima i onih nastalih izvan našega područja, u središtima ondašnje moći - Veneciji, Firenzi i Rimu - čiji su autori ondašnji najviši autoriteti i o čijim je odlukama ovisila sudbina osnovanih samostana. To su pape i duždevi. Iako smo rekli da su isprave sastavljene latinskim i talijanskim jezikom te na pismima svoga vremena, goticom i humanistikom, na poleđini uvijek imaju regestu, koja je najčešće sastavljena glagoljicom na hrvatskom jeziku.

Najstariji dokumenti, osobito zanimljivi medievistima, jesu oni sa zadarskog područja, koji su nastali već u 14. stoljeću. Dakle, pripadaju vremenu pojave prvih trećoredskih pojedinaca i zajednica. Oni, ali i dokumenti iz 15. stoljeća, s gledišta trećoredske, ali i hrvatske povijesti, općenito pobuđuju najveći interes. Veliku pomoć pri hodu kroz ovu neveliku zbirku pruža nam spomenuti arhivistički inventar: Arhiv Provincije franjevaca trećoredaca - Regeste pergamena. Skretanjem pozornosti na njih ujedno se upozorava da se mogu očekivati još ovakve pojedinačne diplomatičke zbirke, koje bi svakako trebalo uključiti u Akademijin projekt Supplementa Codicis diplomatici Regni Croatiae, Dalmatiae et Slavoniae.

Sam pak inventar sadrži regeste oko 350 dokumenata, od čega ih srednjem vijeku, odnosno 14. i 15. stoljeću, pripada oko 80. Pokušavajući dati kratak prikaz ove diplomatičke arhivske zbirke, težište ću staviti na posebno zanimljive cjeline.

Već površan pogled u sadržaj te vrijeme i mjesto nastanka skupine navedenih srednjovjekovnih isprava precizno omeđuje prostor javljanja i nastanka ove samostanske zajednice u Hrvatskoj. Naime, Zadar i zadarsko okruženje uglavnom su zastupljeni među dokumentima 14. i 15. stoljeća. Iako regeste u inventaru nisu sasvim ujednačene - kako se navodi u uvodu - jer ih je radilo više arhivista, ipak su napravljene lege artis i pružaju sve osnovne podatke iz kojih se može iščitati sadržaj, pa onda i njihova važnost. S obzirom na pravni čin, isprave su vrlo različite, ali u ovakvom su korpusu upravo takve i očekivane. Ima javnih i privatnih isprava. Privatne su isprave mahom notarskog podrijetla, a javne su izdali visoki crkveni, ali i javni autoriteti. Od javnih isprava svakako su najvažnije 
papinske bule, pa slijede one isprave koje su izdali zadarski nadbiskupi. Među bulama, neke su vezane upravo uz nastanak samostana na hrvatskom prostoru, a neke su općenitog karaktera. Svi ovi dokumenti neposredno se tiču trećoredskih samostana te na razini svoga vremena pravno reguliraju različite situacije. Tako se u notarskim instrumentima zrcale raznoliki imovinski odnosi, koji su utkani u sâm nastanak samostana, ali ima i onih koji se tiču drugih osoba. Prema svom sadržaju, svjedočanstva su to različitih načina darovanja (neposredno ili oporučno), zatim provođenja oporuka i različitih poslova te pitanja koja su se pojavljivala u proceduri prijenosa darovanja. Ima i kupoprodajnih ugovora, zamjena posjeda i slično. Autori su privatnih dokumenata građani, koji su trećoredske zajednice obdarivali posjedima, zemljištima, zadužbinskim crkvenim zdanjima ili novcem, kao i oporučnim legatima te su omogućili utemeljenje pojedinih samostana.

Zanimljiva je i u toj skupini vrlo važna listina darovnica zadarskog nadbiskupa Laurencija Venerija, izdana 4. prosinca 1439. Taj zadarski nadbiskup crkvu sv. Ivana izvan zidina u Zadru dodjeljuje fra Martinu i njegovim pustinjacima trećorecima, a patronatsko pravo, uz obvezu popravka crkve i gradnje samostana, bogatomu zadarskom trgovcu Grguru Mrganiću od roda Virevića. ${ }^{2}$ Ispravu je u integralnom obliku objavio fra Stjepan M. Ivančić u svojim Prilozima. ${ }^{3}$ Ovu bismo ispravu mogli mutatis mutandis smatrati fundacijskom listinom toga zadarskog samostana jer kada bi ovaj samostan sastavljao kartular, ona bi u njemu bila na prvome mjestu. Više je dokumenata sličnoga fundacijskog sadržaja izdano o samostanu na Školjiću (Galevac). ${ }^{4}$ Tako npr. papa Eugen IV. u buli upućenoj 28. svibnja 1442. zadarskomu nadbiskupu traži provedbu darovnice, dobivene prema oporuci bogatoga zadarskoga građanina Bartola Marinova iz Milana (de Milano), kojom je ovaj ostavio da se od njegovih dobara sagradi trećoredski samostan $\mathrm{s}$ oratorijem i svim ostalim pratećim objektima na Školjiću jer se njegovi izvršitelji oporuke za to nisu pobrinuli. Konačno, postupak izvršenja oporuke okončan je i posvjedočen dokumentom od 4. srpnja 1446., kojom trećoreci preuzimaju zadužbinu Bartula de Milano s crkvom sv. Pavla na otočiću Galevcu blizu Preka te se upravo ona može smatrati fundacijskom listinom ovog samostana. Koliko je bila složena situacija dolaskom trećoredaca na Školjić (Galevac), kao i izvršenje oporuke Bartola de Milano svjedoče i drugi dokumenti, koji se ne nalaze u ovoj zbirci, a nadopunjavaju se s onima iz Državnog arhiva u Zadru koje je naveo E. Hilje. ${ }^{6}$ Tako se i bula pape Nikole V. od 10. siječnja 1453. nalazi u ovoj zbirci;

\footnotetext{
HILJE 2003: 16-17.

IVANČIĆ 1910b: br. I, 3-4.

4 Usp. RUNJE 2012: 139-155 (poglavlje: Samostan sv. Pavla na Školjiću u srednjem vijeku).

5 Ivančić (1910: 205) ga kroatizira u Bartula Milanju te navodi da je bogobojazan zadarski plemić.

6 HILJE 2003: 7-19.
} 
njome se zadarskomu nadbiskupu nalaže izdavanje apostolske potvrde za obje prethodno spomenute crkve, odnosno samostana, a objavljena je u Ivančića. ${ }^{7}$ Konačno, zadarski je nadbiskup Mafej Valareso 4. srpnja 1456. izdao dokument o tome da je izvršio taj papin nalog iskazan u buli, koju donosi kao uvodni dio u transumptu.

I druge samostanske zajednice, koje su tada nastajale na zadarskom području, morale su se obraćati crkvenim vlastima za okončanje darovnica. Tako je već spomenuti Grgur Mrganić, zadarski građanin koji se vrlo često pojavljuje u dokumentima o kojima izvješćujem, a što znači da je znatno utjecao na učvršćivanje trećoredske samostanske zajednice u Zadru i njegovoj okolici, trećorecima darovao svoj posjed u Zaglavu na Dugom otoku. ${ }^{8}$ Time je začet trećoredski samostan na tom otoku. Taj je dokument u popisu inventara datiran 1451., a tako je objavljen i u Ivančića. ${ }^{9}$ Pogrešku u dataciji zamijetio je Hilje te ju je ispravio. ${ }^{10}$ Ispravno je utvrdio da se radi o 1452. jer su zadarski notari upotrebljavali stilus incarnationis pri datiranju izdavanih isprava. Iako u zadarskom arhivu ima više drugih i drukčijih isprava o gradnji ove crkve, one se odnose na zadužbinu koju je kasnije Grgur Mrganić darovao trećorecima upravo ovom ispravom te je možemo smatrati fundacijskom listinom zaglavskog samostana.

$\mathrm{U}$ nizu trećoredskih isprava koje bismo mogli nazvati fundacijskima nalazi se i ona datirana 28. travnja 1463., o zemljišnoj darovnici šibenske općine za podizanje samostana trećoredaca i crkve na otoku Prviću. Donosi je, dakako, i Ivančić. ${ }^{11}$ Sadržajno je zaista riječ o fundacijskoj ispravi samostana i crkve sv. Marije od Milosti na Prviću, koju notar šibenske kancelarije naziva instrumentum concessionis.

Samostan sv. Marije od Anđela na Bijaru kraj Osora (extra muros Auserenses in loco Viar vulgariter nuncupato) osnovan je zaslugom Stjepana Sbare, koji je trećorecima na raspolaganje dao dio naslijeđene baštine izumrle obitelji De Romeis, što je darovnicom s istoimenom crkvom od 4. lipnja 1465. potvrdio osorski biskup Antun Palčić, rodom Pažanin. ${ }^{12}$ U posjed je uveden dokumentom od 13. studenoga 1466.

Za razliku od drugih mjesta, gdje su se u osnutku trećoredskih samostana uglavnom isticali bogati građani, na Krku su presudnu ulogu u osnutku najstarijega trećoredskog samostana imali knezovi Frankapani. Samostan je otvoren u njihovoj

IVANČIĆ 1910: br. VI, 7-9.

Usp. JELIĆ 1960: 487-508.

IVANČIĆ 1910: br. V, 6-7.

1 HILJE 2003: 17.

11 IVANČIĆ 1910: br. VII, 9-10.

12 Usp. IVANČIĆ 1910: 234. 
ladanjskoj kući i na njihovu dobru u najzapadnijem dijelu otoka na Glavotoku, a zahvaljujući strpljivu radu i povjerenju stanovništva, postat će najbogatiji i, uz Zadar, najvažniji trećoredski samostan. Posljednji krčki knez od roda Frankapana, Ivan VII. Frankapan, 1468. darovao im je kapelu i zemlje na Glavotoku ${ }^{13}$, a 18. ožujka 1480. zbog iskazane će im vjernosti potvrditi sam samostan. ${ }^{14} \mathrm{U}$ kontekstu spomenutog kneza promatra se i osnutak dubašljanskog samostana, koji je u početku, kao kuća s pripadajućom kapelom sv. Marije Magdalene, pripadao već postojećemu glavotočkom samostanu sv. Marije. ${ }^{15}$

Na sličan bismo način mogli otpratiti sve samostane, tražeći njihove fundacijske isprave. Svakako treba naglasiti da se u ovoj zbirci isprava nalaze i papinske bule. Neke, koje se tiču rješavanja pitanja vezanih uz osnivanje samostana, već smo naveli. Međutim, za djelovanje čitave provincije, koja se službeno nazivala Dalmatinsko-istarska provincija sv. Jeronima, niz je papinskih bula kojima se reguliraju njezin ustroj, konstitucije i pravila. Izdvajamo opća pravila pape Nikole V. iz 1453., koja se donose u prijepisu, te dvije bule pape Siksta IV. iz 1473. Prvom naređuje provincijalu i redovnicima da se okupe na kapitulu i izaberu neovisnog poglavara za provinciju, a drugom da između sebe biraju vizitatora, pozivajući se na povlasticu pape Inocenta IV., po kojoj su franjevci trećoreci glagoljaši bili jedinstveni u franjevačkom svijetu.

Ovim smo skrenuli pozornost tek na neke, po mojoj prosudbi, važnije isprave iz provincijskog arhiva, koje su utkane u samu povijest ovog Reda. Upravo je to i cilj ovog priloga: općenito usmjeravanje zanimanja i prema ovakvim, ne baš poznatim i dostupnim, zbirkama dokumenata, koje nisu važne samo za ustanovu u kojoj se čuvaju, nego su vrelo podataka i o drugim aspektima života. Najstarije srednjovjekovne isprave franjevaca trećoredaca glagoljaša zbog razine pismenosti imaju osobitu vrijednost kao svjedočanstvo o nastanku jednog reda na hrvatskom prostoru. One pak kasnije imaju svoju drugu vrijednost. Ponajprije su svjedočanstvo pojedinih samostanskih zajednica, njihov trag, sve dok samostanski dokumenti nisu objedinjeni u zajednički arhiv za čitavu provinciju. I ovi su dokumenti pisani latinskim jezikom i humanistikom, ali se sve više pojavljuju i oni zapisani talijanskim jezikom.

Među ovim ispravama, kojih je dvjestotinjak, ima i onih koje se neizravno tiču svojih samostana te sadržajno dotiču pravne i druge aspekte ondašnjega lokalnog društva. Uglavnom su to notarski instrumenti o kupoprodaji zemljišta i kuća, ali i oporuke. Često u tim pravnim poslovima nijedna stranka nije bila iz samostana, a ima i takvih gdje je jednu stranu zastupao upravo neki franjevac. Ove isprave

13 Usp. RUNJE 2003: 38-51, 116-128; Isti 2005.

14 IVANČIĆ 1910: br. XX, 24.

15 IVANČIĆ 1910: 225. 
našle su se među samostanskim dokumentima jer su trećoredski samostani zbog osamljenosti i povjerenja bili sigurna mjesta za čuvanje takvih privatnih dokumenata. Nije ovdje riječ o ustanovama javne vjere, odnosno loca credibilia, koje su izdavale dokumente, nego su trećoredski, ali i drugi samostani imali ulogu arhiva, pouzdanih i sigurnih mjesta. Iako se često za ovakvu djelatnost koristi i termin vjerodostojno mjesto, u diplomatici loca credibilia označavaju tehnički termin koji ima sasvim jasno značenje. Zanimljiva je, ali i objašnjiva činjenica da se među njima nalazi najviše dokumenata s otoka Rave, na kojem su trećoreci imali svoje posjede.

Na kraju bih preporučila da se u projekt HAZU Supplementa Codicis diplomatici Regni Croatiae, Dalmatiae et Slavoniae svakako uključi šest ili sedam trećoredskih dokumenata iz 14. stoljeća. Koliko znam, taj fond u dosadašnjim istraživanjima nije bio obuhvaćen. $\mathrm{Na}$ isti način, prilikom pripremanja nekih drugih diplomatičkih izdanja, osobito potencijalnog Diplomatičkog zbornika XV. stoljeća, ili možda nekog drugog, treba uključiti i druge dokumente, a mislim da nijedan Codex diplomaticus fratrum Tertii ordinis regularis sancti Francisci ne bi bio naodmet.

\section{Bibliografija}

Arhiv Provincije franjevaca trécoredaca-Regeste pergamena. 1980. Ur. Petar Runje. Zagreb: Provincijalat franjevaca trećoredaca (umnoženo kao prilog Vjesnika franjevaca trećoredaca 3-4, 5-6 [1979]; 1-2 [1980]).

HILJE, Emil. 2003. Utemeljenje franjevačkih samostana na zadarskim otocima. Radovi Zavoda za povijesne znanosti HAZU u Zadru 45: 7-19.

IVANČIĆ, Stjepan Nauč. (prir.). 1910. Povjestne crte o samostanskom III Redu sv. O. Franje po Dalmaciji, Kvarneru i Istri i poraba glagoljice u istoj redodržavi. Sa prilozima. Zadar: Odlikovana tiskarna E. Vitaliani.

JELIĆ, Roman. 1960. Grgur Mrganić. Radovi Instituta Jugoslavenske akademije znanosti i umjetnosti u Zadru 6-7: 487-508.

RUNJE, Petar. 2003. Povijest Glavotoka [I-II]. Vjesnik franjevaca trećoredaca glagoljaša $\mathrm{XL} / 1: 38-51 ; \mathrm{XL} / 2-3$ : 116-128.

RUNJE, Petar. 2005. Glavotok. Svetište Majke Božje. Glavotok: Samostan sv. Marije.

RUNJE, Petar. 2012. Prema izvorima II. Rasprave i članci o hrvatskim franjevcima trećoredcima glagoljašima. Ur. Tomislav Galović [Novaja i vethaja 9; Krčki zbornik 68, Posebno izdanje 61]. Zagreb: Provincijalat franjevaca trećoredaca, Povijesno društvo otoka Krka. 


\section{Collection of Deeds in the Archives of the Province of Tertiary Franciscans}

The Franciscan Provincial Archives on Ksaver in Zagreb keeps a collection of parchments, or rather diplomatic documents in Latin and Italian language. The deeds come from a long period of time ranging from the $14^{\text {th }}$ to the $18^{\text {th }}$ century. Based on an insight into the archival aids, i. e. their inventory, as well the material itself, this diplomatic collection will be evaluated in terms of historical studies, since, as the authors of the inventory stressed, it seems to be reflecting in a way the history of the Province itself. It is important to utilise and to acquaint the scientific public with it in order to make it a subject of research for historians dealing with the areas and periods the Province used to occupy.

Keywords: The Franciscan Provincial Archives, Ksaver, Zagreb, collection of parchments, inventory, diplomatic collection

Ključne riječi: Arhiv Provincije franjevaca trećoredaca glagoljaša, Ksaver, Zagreb, zbirka pergamena, inventar, diplomatička zbirka

Mirjana Matijević Sokol

Filozofski fakultet Sveučilišta u Zagrebu HR-10000 Zagreb, Ivana Lučića 3 mmsokol@ffzg.hr 


\section{FILOZOFSKI FAKULTET SVEUČILIŠTA U ZAGREBU \\ ZAVOD ZA HRVATSKU POVIJEST \\ INSTITUTE OF CROATIAN HISTORY \\ INSTITUT FÜR KROATISCHE GESCHICHTE}
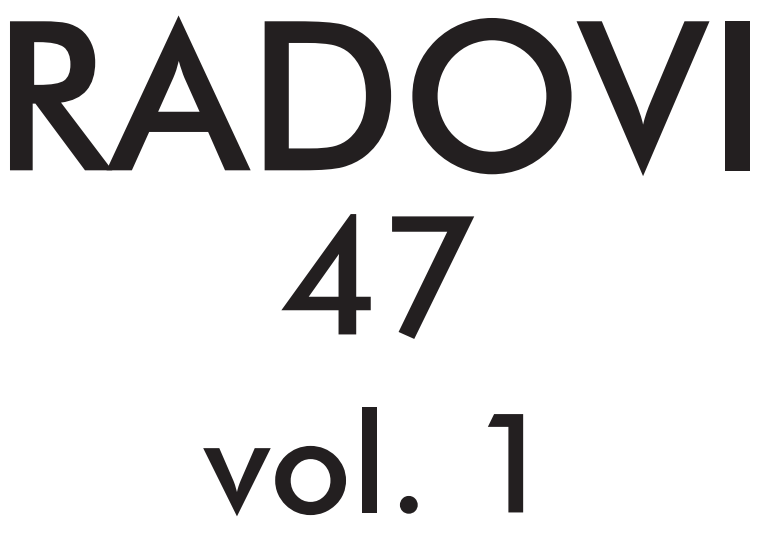

ZAVOD ZA HRVATSKU POVIJEST

FILOZOFSKOGA FAKULTETA SVEUČILIŠTA U ZAGREBU

\section{PF press \\ ZAGREB 2015.}




\title{
RADOVI ZAVODA ZA HRVATSKU POVIJEST FILOZOFSKOGA FAKULTETA SVEUČILIŠTA U ZAGREBU
}

\author{
Knjiga 47, vol. 1
}

\author{
Izdavač / Publisher \\ Zavod za hrvatsku povijest \\ Filozofskoga fakulteta Sveučilišta u Zagrebu \\ FF-press \\ Za izdavača / For Publisher \\ Vlatko Previšić \\ Glavni urednik / Editor-in-Chief \\ Hrvoje Gračanin \\ Izvršna urednica / Executive Editor \\ Inga Vilogorac Brčić \\ Uredništvo / Editorial Board
}

Bruna Kuntić-Makvić (stara povijest/ancient history), Zrinka Nikolić Jakus (srednji vijek/ medieval history), Hrvoje Petrić (rani novi vijek/early modern history), Željko Holjevac (moderna povijest/modern history), Tvrtko Jakovina (suvremena povijest/contemporary history),

Silvija Pisk (mikrohistorija i zavičajna povijest/microhistory and local history),

Zrinka Blažević (teorija i metodologija povijesti/theory and methodology of history)

Međunarodno uredničko vijeće / International Editorial Council

Denis Alimov (Sankt Peterburg), Živko Andrijašević (Nikšić), Csaba Békés (Budapest), Rajko Bratož (Ljubljana), Snježana Buzov (Columbus, Ohio), Svetlozar Eldarov (Sofija), Toni Filiposki (Skopje), Aleksandar Fotić (Beograd), Vladan Gavrilović (Novi Sad), Alojz Ivanišević (Wien),

Egidio Ivetić (Padova), Husnija Kamberović (Sarajevo), Karl Kaser (Graz),

Irina Ognyanova (Sofija), Géza Pálffy (Budapest), Ioan-Aurel Pop (Cluj),

Nade Proeva (Skopje), Alexios Savvides (Kalamata), Vlada Stanković (Beograd), Ludwig Steindorff (Kiel), Peter Štih (Ljubljana)

Izvršna urednica za tuzemnu i inozemnu razmjenu / Executive Editor for Publications Exchange Kristina Milković

Tajnik uredništva / Editorial Board Assistant

Dejan Zadro

Adresa uredništva/Editorial Board address

Zavod za hrvatsku povijest, Filozofski fakultet Zagreb, Ivana Lučića 3, HR-10 000, Zagreb

Tel. ++385 (0)1 6120 150, 6120 158, faks ++385 (0)1 6156879

Časopis izlazi jedanput godišnje / The Journal is published once a year

Časopis je u digitalnom obliku dostupan na / The Journal in digital form is accessible at Portal znanstvenih časopisa Republike Hrvatske „Hrčak“ http://hrcak.srce.hr/radovi-zhp

Financijska potpora za tisak časopisa / The Journal is published with the support by

Ministarstvo znanosti, obrazovanja i športa Republike Hrvatske

Časopis je indeksiran u sljedećim bazama / The Journal is indexed in the following databases:

Directory of Open Access Journals, EBSCO, SCOPUS, ERIH PLUS 
Naslovna stranica

Iva Mandić

Grafičko oblikovanje i računalni slog

Marko Maraković

Lektura

Samanta Paronić

Tisak

Web2tisak, Zagreb

Naklada

250 primjeraka

Časopis je u digitalnom obliku dostupan na Portalu znanstvenih časopisa Republike Hrvatske ,Hrčak“ http://hrcak.srce.hr/radovi-zhp

The Journal is accessible in digital form at the Hrcak - Portal of scientific journals of Croatia http://hrcak.srce.hr/radovi-zhp 


\section{RADOVI 47}

\section{vol. 1}

ZaVoda za hrVAtSku poviJest FILOZOFskoga fakulteta SVeuČILIŠTA u Zagrebu 


\title{
Tematski blok / Themed issue
}

\section{TREĆOREDSKA GLAGOLJAŠKA TRADICIJA U EUROPSKOM KONTEKSTU TERTIARY GLAGOLITIC TRADITION IN EUROPEAN CONTEXT}

\author{
Radovi međunarodnoga znanstvenog skupa \\ održanoga 27. i 28. IX. 2013. na Hrvatskom katoličkom sveučilištu u Zagrebu \\ u organizaciji \\ Provincije franjevaca trećoredaca glagoljaša u Zagrebu, Hrvatskoga katoličkog \\ sveučilišta u Zagrebu, Filozofskoga fakulteta Sveučilišta u Zagrebu - Odsjek za \\ povijest, Filozofskoga fakulteta Sveučilišta u Splitu - Odsjek za povijest, Instituta \\ za povijest umjetnosti u Zagrebu i Staroslavenskoga instituta u Zagrebu \\ Proceedings of the International Scientific Conference \\ held on 27th and 28th September 2013 at the Catholic University of Croatia in Zagreb \\ and organized by \\ the Province of the Glagolitic Friars of the Third Order Regular, Catholic University \\ of Croatia in Zagreb, Faculty of Humanities and Social Sciences of the University \\ of Zagreb - Department of History, Faculty of Humanities and Social Sciences of \\ the University of Split - Department of History, Institute of Art History, \\ and Old Church Slavonic Institute
}

Gosti urednici / Guest editors

\author{
Ivan BOTICA \\ Tomislav GALOVIĆ \\ Kristijan KUHAR
}

